\title{
Resurgence of Second Wave of Pandemic Covid-19 and Its Impact on Physical and Mental Well-Being of Employees \& Coping Mechanism
}

\author{
Dr. Meenakshi Kaushik ${ }^{1} \quad$ Dwaipayan Guha $^{2}$ \\ 1.Professor, Head, PGDM department, Accurate Group of Institutions, Knowledge park -3, Greater Noida, Uttar \\ Pradesh-201306 India \\ 2. General Manager, Human Resources, JWIL Infra Limited, Jindal ITF Centre, Shivaji Marg, Moti Nagar, New \\ Delhi -110015ndia
}

\begin{abstract}
COVID 19 has had a far-reaching impact on the world since it appeared in November / December 2019. No country has escaped the wrath of this pandemic. Even developed countries in Europe, America, South America and various Asian countries were totally inundated with cases of COVID 19. The global healthcare system has completely collapsed and countries struggled to cope with the huge rush of cases. Initially, most governments did not know how to respond to the emerging situation and most countries reacted by imposing strict lockdown and maintaining social distancing protocols by using masks, gloves, sanitizer, PPE kit and by trying to improve healthcare system. The world had not seen such humanitarian crisis since the Spanish Flu of 1918. This second wave of pandemic covid is really a great concern for the organizations as it's going to have a far-reaching impact on the mental health and wellbeing of people across the globe. As the cases are increasing at such a fast pace in India and death rates are very high, therefore few state governments had to take the decision to impose lockdown and curfews for saving lives. The business world is continuously learning and adapting towards this change of pandemic Covid -19. The second wave of pandemic COVID -19 causing infection rates and death rates very high resulting and increasing incidence and severity of Mucormucosis.Immuno-suppressive treatments are being widely used for the treatment of pandemic COVID -19 infection. People are living in congregating setting and facing more barriers to healthcare. This paper mainly focuses on Resurgence of Pandemic COVID -19 and its impact on people in society including Employees in organizations. This research paper is also studying the impact of the second wave of COVID -19 on physical and mental well-being of people and most importantly coping strategies to be taken into consideration by employers or managers to get more positivity and enthusiasm from their people. This paper also gives insights about Indian central and state government's approach and efforts to manage this pandemic crisis especially in India during second wave of pandemic COVID -19. This research paper will also give light on few important issues such as crisis management in India, vaccination process and other related issues.

Keywords: Second wave of Pandemic COVID -19, Lockdown, Social distancing, COVID protocols, vaccination, physical health and mental health, healthcare, infrastructure, oxygen plants, front line workers.
\end{abstract}

DOI: $10.7176 / \mathrm{EJBM} / 13-10-12$

Publication date:May $31^{\text {st }} 2021$

\section{Introduction}

The 2019-20 crown infection pandemic is a ceaseless pandemic of corona infection ailment 2019 (COVID-19) realized by a corona infection (SARS, CoV-2). The flare-up was recognized in Wuhan, China, in December 2019. However, because of initial mishandling by multi-lateral bodies like WHO, people were allowed to travel globally which led to spreading of the COVID-19 across the world, thus causing pandemic of epic proportion. It was only on March 11th, 2020 three months after the initial detection of COVID 19, that the WHO declared it as a pandemic. The COVID-19 is likely to lead to certain permanent or long-lasting impact (Kaushik \& Guleria,2020). To overcome all these adverse situations and to control the spread of corona virus, several measures were suggested by WHO and various other health agencies. people across the globe should maintain physical distancing, wearing masks, PPE kits at public places, frequent hand-washing, sanitizer usage, avoiding being part of any gathering places like theatres, school/colleges, workplace, mall, religious places became integral part of life (Bavel, et al). The first case of the COVID-19 pandemic in India was reported on 30 January 2020 in the state of Kerala and the affected person had a travel history from Wuhan, China (Wikipedia). The first death due to COVID-19 was reported in India on March 12, 2020. When COVID-19 outbreak started spreading across the world, thousands of people started facing severe health related and breathing issues and led to increased death-rates. The only solution to break the corona virus spread was to stop all activities in affected countries by imposing partial or complete lock-down, curfews for an indefinite period of time and that is still going on in some parts of the globe. Under such circumstances, all business activities in organizations and industries were completely stopped. The impact of COVID-19 can be seen in all sectors. Due to the lockdown imposed in India, millions of laborers migrated to their native places and millions of people lost their jobs. As a consequence, to the above, global economy suffered 
catastrophically since early 2020. By the end of 2020, there was a hope as the vaccines were being developed by many pharmaceutical companies like Pfizer BIONTECH, EU nodes Astra Zeneca, SK BIO Astra Zeneca, Serum Institute of India, Janssen infectious diseases and vaccines, SINOVAC, Moderna, THE GAMALEYA national centre, Cansinobio, NOVAVAX, Vector state research centre of virology and biotechnology etc. There was a global race to develop vaccine as soon as possible. Many of these vaccines were given expeditious approval by the governments so that the vaccines can be rolled out quickly. At least seven different vaccines across three platforms have been rolled out in countries. At the same time, more than 200 additional vaccine candidates are in various stages of development, of which more than 60 are still in clinical development stage. COVAX is the part of ACT Accelerator which WHO launched with partners in 2020. Still there is a need to speed up the development of safe and effective vaccines against COVID-19. COVAX is assisting and supporting the building of manufacturing capabilities and working with governments and manufacturers to ensure fair and equitable allocation of vaccines for all countries, as safe and effective vaccines will be a game changer. India had weathered well during the first wave of the COVID 19 pandemic. When COVID 19 hit India in February / March of 2020, the government of India took some bold steps like complete lockdown of the country, enforcing social distancing etc. The infection counts and death count in India was far lower than many developed countries like United States, Europe etc. Many of these Western countries had seen second and even third wave of the pandemic in 2020, while India was spared of any further rise in cases in 2020. This led to all round complacency and optimism. Everyone thought, that the endgame of the pandemic in India was nearby. However, in February 2021, India was hit by the second wave of the pandemic, with severe ferocity. This led to complete collapse of the healthcare system with rising death count all around. Different business organizations, industries and people at different hierarchies are facing various kinds of challenges on people, place, information, resources, infrastructure and machineries and equipment's front .Physical access including commuting has been limited .Engaging with customers and stakeholders have become very challenging this time as everything is happening on phone and via internet .There is an urgent need to change schedules to support demands ,revise employee policies related to work ,remote working access ,reimbursements, tackling salary delays issues ,morale and collaborations, safety standards, Increased communication to employees ,shop-floor workers and field workers, proper and continuous communications with shareholders and stakeholders ,timely work completion and productivity considerations and information sharing and posting issues to be tackled properly to boost the morale of their employees. So a proper understanding of employees issue also assists organizations to take some steps on a priority basis in understanding and analysing various issues on a serious note proactively and taking corrective measures and decisions to tackle present issues and future related events on time at hand .

\section{Need of the study}

The sudden resurgence of the second wave of Covid -19 in February 2021, with another strong strain has not only deteriorated the physical health of the people all across the globe, but also have taken a toll on the mental health of the people and gave rise to anxiety, uncertainty, hopelessness and helplessness, low-morale, breathing issues, depression and panic attacks. Lakhs of people are dying due to scarcity of oxygen supply, medicines and critical healthcare infrastructure. After prolong sufferings and continuous lockdown and curfews for several months in 2020, the coronavirus pandemic ravaged the lives of numerous Indians. This second ferocious COVID wave has led to daily infection number of over 400,000 cases daily in India, thus overwhelming the complete healthcare system. Big religious gatherings, the re-opening of public places like markets, malls, theatres, parlors, hotels and crowded election rallies are responsible for increasing COVID cases in India. Over a period of time, people became complacent, careless and very few used masks and sanitizer. As on $1^{\text {st }}$ may, 2021, total corona virus cases in India are 19,543,236. Number of deaths are 215,353 and recovered cases till so far are 15,976,267 as per the data record available. The second wave has unleashed a gigantic healthcare scare. The way the pandemic morphed; it can be called 'The Hydra-Headed' monster. Given the background of the first wave of COVID 19, where numerous people died in India as also in other parts of the world, including some of the known developed economies of the world, it is but suffice here to ask whether the second wave of the pandemic could have been averted to a lesser extent if not fully in India? This leaves us with a callous attitude towards maintenance of protocol of Covid management in the world. So, there is an urgent need to explore more about second wave of pandemic COVID 19 and its impact on the society as a whole and organizational people. There is also an urgency to see the various COVID protocols to be followed by people in urban and rural area as well. Government should also assign duty to responsible people like medical interns and other available human resources to educate about this pandemic and vaccination process of India and the globe and other related issues as still in some part of the rural areas and small towns people are not aware of the severe impacts are corona virus .. This research paper is also going to describe about coping mechanism from this pandemic crisis. First wave mainly affected old people whereas second wave is affecting younger people as well. It is likely that any third wave will also include small children. So, government at state and central level need to fasten the vaccination process of people of all age group. 


\section{Objectives of the study}

- To study about second wave of pandemic COVID-19 and main causes of sudden spike of this pandemic COVID -19 second wave and the vaccination process.

- To study the impact of second wave of pandemic COVID-19 on people including organizational employee's physical and mental wellbeing.

- To analyse the factors causing scarcity and crisis in India and abroad countries and also to focus on the various ways to fasten the vaccination process throughout the globe.

- To examine the impact of COVID-19 on work performances of employees during second wave of pandemic crisis period.

- To describe various coping mechanism to overcome physical and mental wellbeing from this pandemic.

\section{Research methodology}

This paper aims to present a deeper insight to analyse the impact of second wave of pandemic COVID -19 that again started since February ,2021 and in India and abroad and its severe impact on physical and mental health of people in general and among the employee's in various organizations during this period of adversity and what all measures are been taken by the government of India and abroad countries and how this severe corona virus is deteriorating people's mental and physical health. This paper also emphasizes on the prevailing situation of second wave of pandemic COVID -19 in India and abroad and how organizations are running their offices through 'Work from Home' mode by usage of digital technology through virtual acclimatization and virtual relationship management .This research paper is basically explorative, descriptive and analytical in nature. Data collection is based on primary data and secondary data. The data collection has been done on the basis of primary and secondary data. Primary data has been collected from observation method \& telephonic interviews conducted from employers, employees and few people Delhi based. The secondary data is collected from existing research articles, journals, publications and other sources. This is completely a conceptual paper based on true facts and has tried to give a crystal-clear picture on real crisis that India and outside countries are facing due to second wave of pandemic COVID -19 at the moment by explaining the real crisis situation in India and abroad, scarcity of resources including human resources, proper hospital infrastructure, oxygen and medicines, ventilators and related equipment's and tools supply to the people. The paper has also described about the mental status of organizational employees during this second wave of pandemic COVID -19 and coping mechanism to be adopted by the organizations and industries .

\section{The Second wave of pandemic COVID-19 and its impact on India and globe}

5.1 India is an ancient country. The land of Brahmanism, Buddhism, Jainism, Islamism and Sikhism. All religions have taught universal solidarity and peace for all. This adage, could have been exploited by the current government to mitigate the circumstances into its favour, in the run-up to the aggressive control of the Covid second wave. How has the government at the centre handled the pandemic is a factor not to be ignored by the future economic and political historians. With the experience of the first wave not being far behind, the government at the centre could have taken adequate measures to face up to the challenge of the second wave. The Government of India had 15 months to prepare for this eventuality. Question comes that why at last moment central and state government had to think about creating hospital infrastructure, creating ICU beds, procuring oxygen cylinders, arranging Covid related medicines like remdesivir at last moment. It is a matter of concern as to why any of them did not cope-up with this crisis management when they were fully aware of the fact that new strain and wave of Corona will be reaching soon with its strong effects. Due to the inaction of the government and avoidance of COVID protocols the citizens of the country had to suffer a lot. Few states like Maharashtra, Chhattisgarh, Delhi, and Uttar Pradesh are facing the severe burnt of the crisis. There is complete, lack of coordination and mutual understanding among state and central government on certain issues like infrastructure, availability of doctors, nurses, and paramedical staff all over the country, supply of oxygen cylinder, ICU Beds, Medicines, steroids and other drugs on time. Despite India being a well-endowed country on all fronts, the country failed in providing basic and critical medical infrastructure, medical equipment's, tools, medicines, steroids, ventilators, staff, nurses, doctors and paramedical staff etc. to the needy. The citizens of the country had to rush from one hospital to another hospital for getting treatment for their loved ones. It really showed a lot of mismanagement on the part of the government and ignorance of people and lack of maintenance COVID protocols. In spite of the fact that COVID -19 had been affecting people in India since last year, India was not prepared for this crisis resulting in unprecedented deaths of lakhs of country people.

\subsection{Aids from the other countries}

Due to the current situation, India is now seeking aids from other countries to bolster the medical infrastructure. More than 40 countries including US, Australia, New Zealand, European and neighboring nations like Bangladesh, 
Bhutan, have committed to provide India with medical equipment's, items, oxygen generators, cryogenic tankers, medicines like remdesivir and tocilizumab to India to combat this battle of unprecedented spike of Covid cases. India is also in touch with few suppliers of medicines and raw materials. The ministry of external affairs has also collaborated with various governmental departments, other nations, private sectors and industry associations to deal with this crisis situation.

\subsection{Urgent need to handle this pandemic by investing in medical infrastructure, medicines, Oxygen plants and other related equipment's and human resources}

India really needs to invest money and resources in establishing more hospitals with proper infrastructure with modern equipment's, tools and medical machines in India, hiring and paying lucrative salary along with all other benefits to the doctors, paramedical staff and invest lot of money in infrastructure, medicines, oxygen plants and all kinds of modern well-equipped facilities and amenities to be one of the strong nations of the country. As the cases were increasing at such a fast pace in India, therefore few state governments had to take the decisions to impose lockdown and curfews for saving lives. This severity of the second wave of the pandemic along with accompanied visuals of dying and desperate people, has impacted the mental health of people of India. The second wave of pandemic Covid -19 is so strong that it is mainly affecting the people with weak immune system mainly damaging lungs of the people and increasing incidence and severity of mucormucosis.Immununo-suppressive treatments are being widely used for the treatment of this infection leading to high death rates or organ failure.

\subsection{Impact of second wave of pandemic COVID -19 \& physical and mental health}

Studies have shown that the prolonged lockdown had major impact on the mental health of vast population of UK leading to increased rates of suicidal tendencies. The study led by the University of Glasgow, examined the effects of COVID 19 during the height of the pandemic. Certain groups are said to be particularly at risk, including young people and women. The study found that suicidal thoughts increased from $8.5 \%$ to $10 \%$, highest among the young adults (18-29 years), rising from $12.5 \%$ to $14 \%$. Levels of anxiety, suicidal tendencies and hopelessness are directly associated with the huge social and economic uncertainty associated with Covid -19. Young people, children, women, people from weaker and disadvantaged section of the society, and people already facing severe chronic diseases and pre-existing mental problems are facing worse situations. In England, NHS mental health services have been adapted to provide additional support, including digital appointments, and funding has also been provided to the charities dedicated to improving mental health. Wales has appointed a dedicated minister for mental health, while Scotland and Northern Ireland have both launched mental health action plan. The study published in the British journal of psychiatry, looked at three blocks of time between march 31 and May 11. Over 3000 adults in UK were surveyed and a range of mental health factors were considered including depression, loneliness, suicide attempts and self-harm. There was tremendous increase in Suicidal thoughts among the surveyed people. This second wave of Covid is so severe that it's not only affecting people of all age group but also affecting people who are vaccinated so as such there is no guarantee that vaccinated people won't get affected. This is completely dependent on the strong immunity system of the individual. The overall COVID - 19 cases in the country have risen to $1,45,26,609$ and death rates have reached up to 1,75,49 with Maharashtra leading the pack with maximum cases of infections and deaths., followed by Uttar Pradesh, Delhi, Chhattisgarh and Karnataka. Maharashtra finally decided to impose emergency curfew in the state in the name "Break the Chain" as a precautionary measure and to save lives of people.The US' Centres for Disease Control and Prevention (CDC) stopped its citizens to travel to India due to very high level of covid-19" in India. Britain has added India in its COVID-19 travel "red list", which bans all travel from the country and makes a 10-day hotel quarantine mandatory for UK residents returning to the country. Situation is so severe that hospitals are not even in a position to take admit people and even labs are avoiding taking more tests of corona patients.

\subsection{Resilience}

Resilience acknowledges that there is no one-size-fits-all approach to facing organizational challenges (Khalil M. Dirani, Mehrangiz Abadi, Amin Alizadeh, Bhagyashree Barhat, Rosemary Capuchino Garza, Noeline Gunasekara, Ghassan Ibrahim \& Zachery Majzun,2020). COVID period has made HR personnel and organizational employers to re-think on certain issues regarding motivating, inspiring and training and developing the people and adoption of a system of imparting skilling (learning new skills for being competent in upcoming days, adversity or adversity or any crisis); up-skilling (learning current tasks more deeply); as this is the need of the hour to learn and understand new technology as well as manage relationships to fit into the changing scenario and economic landscape. People need to be updated on technology, design thinking, storytelling, and artificial intelligence etc. People at grass root level and working at lower profile are required to be trained on accomplishing their tasks and reporting about their developments to their supervisors either by mobile or any other platform. So, this way, making people competent and multi-skilled in a variety of ways and enhance their skill sets. When pandemic outbreak emerged, employees were bound to stay at home and work from home due to announcement of lockdown 
and maintaining social distancing. It was very difficult for all the employers to manage their employees as that time they could only see and interact with each other on a digital platform such as zoom meet, google meet, skype and WhatsApp meet and other platform. During this crisis period, it was the employer and HR manager's duty to create a work culture of people working from home (WFH) mode. While WFH mode became a norm, the HR needed to focus on maintaining an emotional and mental balance and keep employees on high spirts as balanced life always boost energy and efforts to perform productivity from these. It is also referred to the development of trust among the employees which leads to the creation of better and enhancing working environment that is highly progressive and productive in nature (May, Gilson and Harter 2004). During this crisis period, employees are required to maintain a work life balance and people needed to believe in meditation and spirituality at home for better and higher productivity. As per Karwar Singh Kodwani (2012) points of view, manufacturing and service industries are most vulnerable industries where the employees are used to carry out tedius job along with satisfying the needs of the consumers and meeting their expectations. According to Colquitt LePine and Wesson, (2009), even the management of the organization aims at achieving the high performance from the employees. During Covid employees also needed mental and physical well-being by exercising spiritual value practices and meditation as it improves the performance level of employees and increases the productivity and profitability in the organization. The inclusion of spiritual value and trainings on emotional and mental wellness at workplace could help the employees to repair the lost strength and to reduce the stress level to a minimum. This should enable organizations to maintain healthy work culture for improving the employees mental and physical well-being. According to Caallarza Saura, (2006) the presence of positivity spiritual values helps the employees to establish associations and linkages with the other individual at workplace and develop the feeling of trust among oneself. As per the Asger Vazin K Zareeri (2011), the employees are found to have increased level of self-search and are looking for an authentic and purposeful meaning towards work and life.

\section{Literature review}

Pandemic COVID-19 has become a great challenging concern for the whole globe for an indefinite period of time. As a game-changer, pandemic COVID-19 has impacted not only human life but also business organizations and industries on a global front and led to a challenging situation in front of all the employers, managers and all level of people. In a very short span, this affected the whole world and the overall global economy. The impact of pandemic COVID-19 would be very far reaching and long-lasting with no other option left except imposing lockdown and curfew partial or complete all over the world for an indeterminable period of time. this leaded to complete shutdown of few industries. Under all these circumstances, companies were only having one option of running their business by Work from Home (WFH). A paradigm shift has taken place in organizations in many ways and organizations are bound to be in tune with these major challenges, changes and shifts. The impact of pandemic COVID -19 on industries is profound and significant as no one could imagine the extreme action of shutting down all industries and started working Work from Home (WFH) concept through the massive usage of disruptive technology (Kaushik, M.2020). The worldwide lockdown is likely to lead to overall drop in efficiency and compromise monetary development of economies, for a long time. Work from Home is not a new topic that's used during this crisis period but it has been around for longer than 10 years. The COVID19 pandemic has prompted greater number of organizations to work remotely. The term work from home (WFH) came in to existence in 1970s. It is advantageous as it includes adaptable and flexible working hour to the individuals facilitating flexibility in working modes. Organizations are set to rethink seating at workplaces as per social separating standards, present move-based work, go virtual with gatherings (Kaushik \& Gulleria ,2020). Work from home (WFH) is where the individuals can do their jobs from home through disruptive technology via mobile, or other digital platforms, Artificial Intelligence, analytics all have changed the way companies used to run and functioning a business. The main challenge in front of the organizations is to equip its employees with disruptive technologies and to prepare workforce to become more competent and brilliant by improving their proficiency. (Kaushik,M \& Guleria, 2020). Possibly one of the most challenging situations is preventing from the COVID-19 pandemic involves adjusting new and current employees to radically changed working conditions shifting to WFH environment and implementing new working policies and way outs accordingly.

Thus, organizational employers and HR department are required to develop a vision for integrating technology within the organization (Lewis 2010) and technology is used by workers to mediate their activities (Orlowski 1992). Technology has become an important part of the organization and its workers and leaders should be competent to enable the workers in their roles using technology. The organizational culture also plays a pivotal role and an enabler, or a hindrance based on the situation and the way it is implemented by the organizations. A carefully evaluated and thought-out organizational culture can promote the highest productivity possible with better employee relation and engagement. The best technology can yield better productivity only if it is used in an effective way by the qualified and engaged human resources. (Waisfisz and Hofstede). The findings of research conducted by Marc and Tracy suggests that profitable companies exhibited value driven strong culture which are people-centricity, accountability, collaboration, agility, integrity, innovation and ambition (Berman and Thurkow). 
Therefore, organizations are required to recognize the significance of promoting and incorporating patience, trust, resiliency and collaboration supported by a robust technological system to guarantee stability and development in difficult times. As stated by Laura and Vanessa in an article published in Harvard Business Review magazine, the boundaries between personal and professional time is also blurring in new and unusual way during the sudden transition to work from home. Days are blending with night and weekdays are mixed with weekend. There is very little sense of time off and holidays. In long run, it is not healthy and in this regard many researches recommend drawing lines between professional and personal lives for good mental health (Giurge and Bohns). To cope-up with the new environment of prolonged work-from- home there is a need to have right skill sets. This will help a homeworker establish right balance between work and home life, client visits, creating a mini-home office away from distractions, technological support etc. (Nickson and Siddons). Work from home policies will greatly benefit those women workers, who have young babies at their homes. This initiative will bring lots of good women talent into the workforce (Gautam). In a survey conducted by job search portal Flexi Jobs in 2019, it was found that around 31 per cent of women employees took unwanted career break after having kids (Reynolds). There are chances that a large number of employees may not want to work from home due lack of productive environment at home. An article published in the New York Times suggests to adopt hybrid approach. However, the flip side is long-term remote working may also increase phycological stress, diluted work life boundaries, communication gap among team members, lack of interpersonal relationship, concern over job security and diminishing organizational culture. To drive a profitable growth successful organization, employees need to adapt themselves for enhanced uses on cutting-edge technology and invest efforts in enhancing their work experience. This may need a lot of training and sensitization for employees to accept the newer ways of working. (Mithilesh Kumar Singh \&Vijay Kumar,2020). Organizational employers and leaders are required to look up to in the future and post-pandemic to help employees overcome several emotional and personal problems and also need to understand each and every individual's problems separately and guide them to overcome them. Rocco and Shuck (2019) presented their views on how leaders and organizations must create a space for employees so they can grieve and express grief. HR department can assist leaders to develop their emotional quotient and emotional intelligence which has been stated as an important leadership trait (Farnia and Nafukho 2016). Technological affordances during pandemic period were largely actualized as supporting functional affordances to complete tasks or as social affordances to connect with remote e-workers and teams. Environmental affordances in the workplace facilitated a wide range of professional and social interactions. When enforced working from home was introduced, a shift in affordances was observed. The workplace environmental affordances were withdrawn, and more features of the technological affordances were perceived and actualized to maintain "business as normal", including those professional and social interactions previously enabled by environmental affordances. In addition to affording previous task-orientated activities, technological affordances (Majchrzak \& Markus, 2012) during the lockdown facilitate a wide range of activities for team collaborations such as, virtual team stand-ups, formal meetings, and after-work virtual drinks. The technological affordances enable equal opportunities of communications regardless of the physical proximity as well as a less hierarchical structure between the leader and team members for communication. (Lena Waizenegger, Brad McKenna, Wenjie Cai \& Taino Bendz,2020). A study published by Rensselaer Polytechnic Institute prior to the onset of Coronavirus indicates that those who work from home on a regular basis while eligible to be considered for promotions are likely to suffer from overall lower pay increases than those given to on-premises employees. Some of the challenges that we are seeing now stem from employers that typically don't support a geographically dispersed workforce.

\section{Discussion and Analysis}

\subsection{Relentless surge in corona virus cases $\&$ vaccination}

Due to sudden spike in covid cases during second wave it was decided by government that till $19^{\text {th }}$ April 2021, only people aged 45 years or above that were allowed to get the doses of vaccination. But this second wave was so severe and chronic that death rates increased tremendously. In response the government announced even people aged 18 years and above will be eligible for vaccination from $1^{\text {st }}$ May, 2021. This announcement of vaccination of above 18 years children is one of four significant shifts in the government's vaccination policy, came at the end of a meeting chaired by Prime Minister Narendra Modi against the backdrop of a relentless surge in coronavirus cases. Apart from this, vaccine manufacturers will be incentivised to further scale up their production, as well as attract new national and international players. Vaccine manufacturers will be empowered to release up to $50 \%$ of their supply to state government and in the open market at a pre-declared price.

\subsection{Increased rate of "second wave of mental health issues"}

During these Pandemic period people are facing loneliness, anxiety and job losses, many had to overcome resistance to acknowledging that they may have a mental health problem and reach out for help. A research paper titled ', published in August 2020, by Shankar Das, mentioned that all large-scale disasters have had a significant negative impact on individuals ranging from depression, post-traumatic stress disorder (PTSD), substance use 
disorder, behavioural disorders, domestic violence and child abuse. The current COVID-19 pandemic is again giving rise to similar problems. There was a significant rise in people reaching out to her for help from three major categories: young adults up to the age of 40, many of whom lost their jobs to the pandemic; students whose dreams of higher studies were shattered as most countries sealed their international borders for months; and children between the age groups of three and four, who were showing many behavioural issues, as they were confined to their homes.

There were many cases of substance abuse by children as they were unable to cope with so much uncertainty. The 'second wave' of the pandemic in India, is bringing about a 'second wave' of mental health concerns too. If one is feeling bogged down or stressed at the moment, it's very essential breaking down one's problems into smaller tasks that are easier to accomplish. During Covid 19 pandemic, Corona affected people, it was necessary to curb the spread of the virus. But somehow it is not advisable to live alone. Such people need to remain ' in touch with friend s, family, relatives, Colleagues with a positive and healthy mindset. A study published by Samantha K Brooks in February 2020, showed that in the past, many studies had reported negative consequences of quarantine including post-traumatic stress symptoms, confusion and anger. Longer quarantine duration, fears of infection, helplessness, frustration, boredom, inadequate information and financial loss created stress.

Home confinement also aggravated problems for victims of domestic abuse. According to a study the situation had aggravated for victims of domestic abuse in the initial week of lockdown itself. The National Commission of Women reported that 214 complaints were received in just the first week of the lockdown, including 58 about domestic abuse. During the first 11 days of lockdown, India's 'Childline' helpline received more than 92,000 distress calls on abuse and violence requesting protection, as reported by PTI It became very traumatic for such young kids, to be confined with their abusers for so many months. Rising unemployment and fear of job losses because of the lockdown added to people's anxiety. Many such people who approached her were apprehensive about sharing their worries with their closest family members because they didn't want them to get anxious. Psychiatrists at leading hospitals in New Delhi also explained and suggested that depressive patients complained of anxiety related to the fear of COVID-19, while some patients expressed fear of being infected, others spoke about uncertainty related to losing their job or familial disturbances. Concerns were expressed over the rising level of disharmony and discords in the family atmosphere due to lockdown, lack of social connectivity for patients and withdrawal symptoms for alcohol and substance users who are habituated and dependent.

A lockdown, on one hand, might be easy for people this time, as they have figured how to navigate their lives around getting supplies online and doing things online, but they might feel like they are going into a sense of loneliness or isolation", In such a tense environment, with a possible lockdown looming, people are really feeling emotionally and mentally gloomy and uncertain. It's true that people are still dealing with multiple fears and anxiety. According to the doctors, the mind usually copes with any unpleasant circumstance with the belief that it's temporary, as the pandemic seemed when it began. But now, when the pandemic does not seem temporary, it is hard for the mind to cope with the stress that comes with this prolonged uncertainty. People need to ensure that all precautions and protocols be followed, to keep themselves safe from COVID-19. Yet some people were detected COVID-19 positive, in spite of following all restrictions. Naturally, people are stressed. With so many possible and often dark scenarios. Covid-19 is a breeding ground for cognitive dissonance. This is a world where a hug is now a threat, avoiding contact is a social nicety, and passing somebody a pitcher of lemonade could lead to a hospital stay.Anxiety is ubiquitous, with restlessness almost a given. These have knock-on effects for the individual and the group. Of course, depression then becomes a risk and a rather nasty spiral can set in. However, stress, uncertainty, and lack of income all contribute to mental overload. Some people have had a good lockdown, of course. They have enjoyed the absence of the daily commute and not being monitored at work. But even here, a lack of normalcy seems to be eating at the corners. The upsides are decreasing. During lockdown, a happy employee was seen to be autonomous, and connected to both friends and colleagues. Pandemic notwithstanding, these psychological engines delivered a strong sense of wellness. This, in turn, meant better engagement across the organization, less stress, higher feelings of creativity and sustained performance. Unhappy workers, meanwhile, suffered across all fronts including their noticeably inferior intellectual performance. These findings carry immense implications for well-being, medical bills and the bottom line. However, while negative effects of prolonged lockdown have been chronicled, studies have also shown that there are some positive as well. Posttraumatic growth helps us build stamina and find possibilities and new opportunities during a career crisis. "That which does not kill us makes us stronger"-Friedrich NietzscheThe pandemic has created a lot of heartbreak, fear and post-traumatic stress disorder (PTSD) among the workforce. On top of our personal woes, many employees have grappled with fears of loved ones and themselves contracting Covid-19, not to mention the isolation and burnout of remote working and helping children with schoolwork. Although many of us have endured a lot of stress and mental health challenges, there's good news on the horizon, known as post-traumatic growth (PTG) the benefits and positive changes that occur from grappling with highly challenging life crises and adversity. 


\subsection{Post-Traumatic Growth}

Thrive Global founder and CEO, Arianna Huffington, said of the pandemic, "Navigating the new normal isn't just about looking out; it's about looking in." Many people have described their struggles with adversity, forcing them to mine their inner reserves, face threats and come out stronger on the other side in their personal and professional lives. When referring to the motorcycle accident that paralyzed him, Sean said it changed him for the better in ways that otherwise wouldn't have been possible. "It was probably the greatest thing that ever happened to me," he said. It caused him to look at his life in a different way and to appreciate things that made living more meaningful. And he's not alone. Recovering alcoholics and drug addicts often report that hitting bottom is their greatest blessing because it wakes them up to a better life - one that is healthier, more productive and more satisfying. When the actor/comedian Richard Belzer was given a cancer diagnosis, he said, "Cancer is a cosmic slap in the face. You either get discouraged or ennobled by it." And in a Barbara Walters interview, the late actress Elizabeth Taylor said she laughed when doctors told her she had a brain tumor. Walters gasped. But Taylor wisely replied, "What else are you going to do?" Oddly enough, Taylor's and Belzer's attitudes show that, when adversity strikes, we can all use it to our advantage.

Studies of trauma survivors show that adversity — as counter-intuitive as it sounds — can actually have certain benefits:

- Help us see we're stronger than we thought

- Bring new appreciation and meaning to our lives

- Change our priorities

- Take us deeper into our spirituality

- Deepen the closeness we feel toward ourselves and others

\section{Recommendation}

1.India needs to urgently support their manufacturers, suppliers monetarily and proper procurement contracts just like other countries United states and European unions as they have extended significant support to vaccine developers as well as manufacturers and at the same time central government and state government needs to be proactive in this regard to save the life of millions of people by being responsible. (amp-scrolin.cdnampproject.org).The government need to be proactive and visionary on many fronts by establishing more hospitals especially multi-speciality hospitals well equipped with modern techniques, oxygen plants ,oxygen ventilators ,ambulances and also improving their hospital infrastructure and policies to reach out to every common people of the country and creating more number medical staff in the country as hospitals specially designated in various states as COVID -19 treatment hospitals forced to adapt using limited infrastructure space, and human resources .All the front line workers like personnel from central and state police, guards ,civil defence volunteers, municipal workers ,prison staff, revenue staff officials engaged in containment and surveillance, disaster management personals, health care workers as doctors, nurses , assistants ,emergency medical technicians should be given the first priority for vaccination. Research shows that vaccines are remarkably very effective and safe so there is an urgent need to do the vaccination process of teens and adults as its important with the rise in cases caused by various strains of the virus that seems to be more contagious. As the new strains of corona virus seem to be very contagious there should a provision to waive the intellectual property rights and boost COVID -19 vaccine production to increase the global vaccines supply.

2.We believe that organizations should allow conversations, stop monitoring and allow autonomy; all of which results in a happy and engaged employee. The results of the research were dramatic and found that happiness is engendered by a combination of active social and business connections, and of being allowed to manage the work flow as the employee saw fit. According to new research by the Society for Human Resource Management, between $22 \%$ and $35 \%$ of U.S. employees are experiencing symptoms of depression as they live through the COVID-19 pandemic. With a large percentage of the global workforce working from home remotely, and by some estimates as much as $42 \%$ of the entire US labour force, it's imperative that employers be aware of the warning signs of mental health issues in their employees and respond proactively by promoting initiatives to prevent and respond to the emotional well-being of employees. Yet, in virtual work environments, the challenge so many employers and managers are facing is how to identify and "spot" the warning signs of those employees in need. 3.Thanks to public health initiatives over the last decades which have raised awareness on mental health education, many in the general population are aware of the warning signs of depression like social withdrawal, changes in mood or increased irritability, absenteeism, decreased productivity, or even anxiety. Yet, these subtle cues are much harder to spot in employees working remotely, so here are some things employers and colleagues should be on the lookout for this coming year as employees continue to work from home.

4.Changes in communication patterns: Perhaps people must be noticing inconsistencies in an employee's communications. They are typically very active by email/slack or other communication channels in the mornings or mid-afternoons, but employers begin to notice long lags, delays or inconsistency in their communication.

Perhaps authorities must haven't heard from them in several days in a row with no advanced notice of their 
absence. Employer really need to see the changes in presentation pattern and to small cues about how employees present in video meetings. Do they seem unkempt, tired, or even dishevelled? This could be a warning sign that they are not doing well. If they begin appearing this way often, this could be a sign of depression. On the contrary, when they present to meetings, do they regularly seem distracted, on edge, or even irritable. If so, these subtle signs could signal anxiety, cancellations, tardiness, forgetfulness its very important to have a close vigil and notice on the changes in performance or consistency.

5.Depression can cause cognitive changes that have an impact on memory, time management and other executive functioning tasks. If employees are showing up late to video meetings, or missing meetings in general which aren't characteristic based on past performance? If so, this is something that managers should address from a compassionate perspective keeping mental health symptoms in mind. Over productivity, working long days or unusual hours.

6. While it may seem paradoxical, being "over productive" may also be a warning sign of emotional or mental health issues especially if someone is coping with their anxiety, stress, or sadness by overworking to avoid their feelings. With the "blur" between home and work being so fuzzy during the pandemic, many people report having a harder time "turning off" their work and as a result this always "on" mentality and contribute to emotional and physical exhaustion and may even contribute to prolonged burnout. One needs to reduce anxiety levels if he /she is more focused on completing your immediate tasks, rather than focusing on the uncertainty the problem brings. 7.One needs to follow to make sure that he /she feeling healthy mentally and physically. That entails eating good healthy food, setting up an exercise regime, maintaining a good sleeping pattern, with sufficient sleep for the body, practising breathing exercises like pranayama and doing yoga, it really helps with the anxiety. Pets and plants are a great way of lifting one' However, while negative effects of prolonged lockdown have been chronicled, studies have also shown that there are some positive as well. Post-traumatic growth helps us build stamina and find possibilities and new opportunities during a career crisis. "That which does not kill us makes us stronger"Friedrich Nietzsche

8. Though many of us have endured a lot of stress and mental health challenges, there's good news on the horizon, known as post-traumatic growth (PTG) - the benefits and positive changes that occur from grappling with highly challenging life crises and adversity. Post traumatic growth and any kind of crisis always forces people and employees to mine their inner reserves, face threats and come out stronger on the other side in their personal and professional lives and change them for the better in ways that otherwise wouldn't have been possible and looking at life in a different perspective and to appreciate things that made living more meaningful.

9.Recovering alcoholics and drug addicts often report that hitting bottom is their greatest blessing because it wakes them up to a better life - one that is healthier, more productive and more satisfying and converting and using adversity for one's own benefits and advantage

10.It's always good to see and find ourselves stronger than we thought and bring new appreciation and meaning to our lives by hanging our priorities and take us deeper into our spirituality by deepening the closeness we feel toward ourselves and others mood. So, it's always advised to keep pets or plants around. Watching feel-good movies that will make you laugh. His Holiness the Dalai Lama contrasted two life situations to show how inner peace and tranquillity are determined more by our state of mind than external circumstances. The first was a woman with meteoric business success who prospered from a financial windfall that suddenly gave her lots of money, free time and retirement at a young age. After the dust settled, her life returned to normal, and the woman said she was no happier than before the windfall. The second was a young man about the same age who contracted HIV. Devastated at the news, he struggled with the shock, exploring his spirituality, appreciating the small and simple things in life, getting more out of each day and feeling happier than before the diagnosis. A recent study examined the positive effects of the coronavirus and its potential for post-traumatic growth. The research surveyed 385 people in Portugal and the United Kingdom during the first wave of Covid-19. Although the respondents reported considerable adversity, $88.6 \%$ also cited four areas of PTG during the pandemic and lock down.48\% described the development of closer, more meaningful family relationships, $22 \%$ cited a greater appreciation of life, adoption of a healthier and slower lifestyle with less stress and more present-moment awareness, $16 \%$ noted spiritual growth, a greater appreciation for others and a stronger sense of community as people helped one another, and $11 \%$ said they embraced new opportunities and possibilities including better work/family balance, positive changes in remote working, plus an opportunity to learn new skills. The researchers concluded PTG can possibly mitigate some of the adverse psychological and mental health effects of the pandemic, which supports findings from published reports of other types of adversity. These findings also validate my early boots-on-the-ground report of collective selflessness and helping others during the pandemic in Asheville, North Carolina.

11.Don't be afraid to ask: With so much stigma surrounding mental health issues in the workplace, managers and colleagues are often afraid of asking how someone is doing. Yet, noticing small warning signs and checking in with the employee shows caring and concern. It may open the door for the employee to share stressors they are experiencing at home or with transitioning to remote work during COVID.

12.Ask your employees what they need: Companies should acknowledge that their employees have unprecedented 
demands during this time. Not only are people struggling with anxiety or concern about the health and safety of themselves, family members, and loved ones, but they are juggling new roles, especially parents with school-aged children who are learning. Leadership and managers need to be compassionate and responsive. Bolster the offerings in your employee wellness program or EAP. Consider quarterly paid, mental health or wellness days, and offering virtual meditation or yoga classes or instituting a "meeting free" block each week. Initiatives like these mentioned paint a clear message to your employees that their health and wellness matters.Consult with specialists to offer wellness webinars: The COVID-19 pandemic has caused a dramatic spike in mental health problems with cases tripling with now one out of every four adults experiencing depression.

13.Yet with the added stress the pandemic is causing, many people may not recognize that what they are experiencing could be classified as an episode of major depressive disorder or anxiety. Companies and employers should consider offering webinars led by mental health specialists who provide education on what signs or symptoms employees should look for.These same specialists can offer virtual workshops or classes to educate employees about proven research strategies that have been shown to boost resilience and combat symptoms of chronic stress, burnout or depression or anxiety. Some of those strategies might include: Creating an end of the work day daily rituals that allow employees to "turn off" work mode and reserve time for down time, being with family, or personal hobbies. Scheduling short breaks throughout the day to talk a brief, brisk walk, or stretch. Regular, aerobic activity has been shown to be as effective as medication and psychotherapy to alleviate symptoms of depression with some studies showing it can increase BDNF, a protein in the brain, while meditative movement like yoga and tai chi has been shown to also relieve symptoms of anxiety. Reserving time every morning before starting the work day to write in a gratitude journal or focus on something or someone that gives a sense of joy. In stressful times, or when someone is experiencing depression, it's natural for the brain's negativity bias to go into overdrive, so it's even more crucial to take opportunities to direct our attention to more positive events.

14. Promote healthy lifestyle habits like encouraging employees to carve out time during the workday to have a proper mid-day meal. Studies have found that diets high in fruit, vegetables, fish and health fats (olive oils) and low in animal products and processed food are associated with a lower risk of depression. Finally, there are now a variety of digital or online treatments with content including video and audio lessons on research-proven techniques to improve mental health. There are many apps that offer guided meditations, breathing practices, and tips and tricks to help you modify your diet and lifestyle to enhance mental resilience and enhance mood. Some of these applications even include regulatory practices like biofeedback or 1:1 support from coaches or licensed mental health professionals.

15.Create opportunities for connection in the workplace: Humans are hardwired for social connection and belonging - meaning that with the pandemic limiting opportunities to connect and having physical proximity with friends, family, colleagues and peers, people are facing social isolation and having feelings of disconnection. Research shows that having one person to connect with results in being ten times LESS likely to be depressed. Even more interesting, one study that tracked seven thousand Californians over nine years and showed that people who have social support, with any form of connection, lived longer than those who did not have any social connection. This means it's imperative for employers to be investing in virtual events, online communities, or even support groups for employees who identify stress or other mental health issues. If one is feeling bogged down or stressed at the moment, it's very essential breaking down one's problems into smaller tasks that are easier to accomplish. During Covid 19 pandemic, Corona affected people, it was necessary to curb the spread of the virus. But somehow it is not advisable to live alone. Such people need to remain ' in touch with friend s, family, relatives, Colleagues with a positive and healthy mindset.

16. COVID period has made HR personnel and organizational employers to rethink on certain issues regarding motivating, inspiring and training and developing the people and adoption of a system of imparting skilling (learning new skills for being competent in upcoming days, adversity or adversity or any crisis); up-skilling (learning current tasks more deeply); as this is the need of the hour to learn and understand new technology as well as manage relationships to fit into the changing scenario and economic landscape. People need to be updated on technology, design thinking, storytelling, and artificial intelligence etc. People at grass root level and working at lower profile are required to be trained on accomplishing their tasks and reporting about their developments to their supervisors either by mobile or any other platform. So, this way, making people competent and multi-skilled in a variety of ways and enhance their skill sets. When pandemic outbreak emerged, employees were bound to stay at home and work from home due to announcement of lockdown and maintaining social distancing.

\section{Conclusion.}

While 2021 will still be a challenging year for many, as the pandemic continues, and remote work will remain the norm, organizations should take a proactive approach to spotting anxiety and depression among their employees and take assured steps to get them the help they need. One must understand, that eventually, we will all come out of this darkness and we will go back to normal work life. While some things in the way companies work have changed permanently, eventually offices will open up, employees will be expected to come to office and work, 
workstations will again become humming with activities, and people will interact face to face and not remotely. Till that happens, companies need to work with their employees providing an enabling and healthy work environment through regular intervention, support and employee mental health programs. There is an urgent need to develop COVID action plan, careful planning and preparation and make it accessible to all the people tailor communication strategies to educate and inform rural people about COVID -19 and ways they protect themselves, coupled wit general education on physical activity, healthy eating, COVID -19 crisis management and coping stress mechanisms. There is also an urgent need to educate people to follow COVID protocols and COVID -19 prevention behaviours and usage of masks, gloves, PPE kits etc. So there is an urgent need to explore more about second wave of pandemic COVID -19 and its impact on the society as a whole and organizational people. There is also an urgency to see the various COVID protocols to be followed by people in urban and rural area as well. Government should also assign duty to responsible people like medical interns and other available human resources to educate about this pandemic and vaccination process of India and the globe and other related issues as still in some part of the rural areas and small towns people are not aware of the severe impacts are corona virus.

\section{References}

AbuMezied, A. (2017). What role will education play in the fourth industrial revolution? World Economic Forum, agenda/2016/01. [Online] Available: https://www.weforum.org/agenda/2016/01/what-role-will-educationplay-in-thefourth-industrial-revolution/

Ahmad, T. (2020). Corona Virus (COVID-19) pandemic and work from home: challenges of cybercrimes and cyber security. Social Science Research Network, doi:10.2139/3568830, http://dx.doi.org/10.2139/ssrn.3568830

Awasthi, A., Dhawan., D. \& Soyav. (2020). Role of Employee behaviour in hospitality industry. INTERNATIONAL JOURNAL OF SCIENTIFIC \& TECHNOLOGY RESEARCH Vol. 9(1).ISSN 22778616

Basu, D. S., Verma, P., \& Malviya, S. (2020). India Inc. resets workspaces for life after COVID-19 lockdown. The Economic Times, article show/75286800

Basu, D. S., Verma, P., \& Malviya, S. 2020. India Inc. resets workspaces for life after COVID-19 lockdown. The Economic Times, article show/75286800.

Berger, P. L., and Thomas Luckmann. The Social Construction of Reality. PDF, Penguin Books, 1991.

Berman, Marc, and Tracy Thurkow. "Covid-19 Creates a Moment of Truth for Corporate Culture." https://www.bain.com, 1 Apr. 2020,

Bevel, Jay J., et al. "Using Social and Behavioural Science to Support COVID-19 Pandemic Response." Nature Human Behaviour, vol. 2020, 30 Apr. 2020, doi.org/10.1038/s41562-020-0884-z. Accessed 15 May 2020.

Buheji, M., Buheji., A. (2020). Characteristics of 'Problem-Based Learning' in Post-COVID-19 Workplace. Human Resource Management Research 2020, 10(2): 33-39 DOI: 10.5923/ /j. hrmr.20201002.02.https://en.wikipedia.org/wiki/2020_coronavirus_pandemic_in_Indiahttps://scroll.in

James, L. (2019). How Industry 4.0 is accelerating business. The record. Retrieved from https:// www.technologyrecord.com/Article/how-industry-40-is-accelerating-business-88964

Kauhik, M. (2020.) Post COVID-19 World- A Paradigm Shift at Workplace. TEST ENGINEERING AND MANAGEMENT. ISSN: 0193-4120. Vol. 83 pp.27675 - 27687.

Kaushik,M., ,\& Guleria, N. (2020). The Impact of Pandemic COVID -19 in Workplace. European Journal of Business and Management. www.iiste.org ISSN 2222-1905 (Paper) ISSN 2222-2839 (Online) Vol.12, No.15,

Kaushik., \& Guleria, N. (2020). The Impact of Pandemic COVID 19 In workplace. European Journal of Business and Management. www.iiste.org ISSN 2222-1905 (Paper) ISSN 2222-2839 (Online Vol.12, No.15.https://www.researchgate.net/publication/342011150_The_Impact_of_Pandemic_COVID_19 in Workplace.

Khalil, $\bar{M}$. Dirani et al (2020). Leadership competencies and role of human resource development in times of crisis: a response to Covid-19 pandemic. Human Resource Development International journal. ISSN: (Print) (Online) Journal homepage: https://www.tandfonline.com/loi/rhrd20.

Kim, Rae Yule. (2020). The impact of COVID 19 on consumers- Preparing for Digital Sales. IEEE. DOI: 10.1109/EMR.2020.2990115 https://ieeexplore.iee.org/abstract/ document/9076858

Kpmg. (2020). Industry 4.0- A competitive advantage from technological transformation. Retrieved from https://home.kpmg/xx/en/home/industries.html

Mani, D., \&Tomar, S. 2020. Work from home in the tome of COVID-19. The Hindu,31207008. https://www.thehindu.com/opinion/op-ed/work-from-home-in-the-time-of-covid-19/article31207008.ece

Ms. Meena et al (2020). Teleworking with autonomy enhances productivity of indian IT professionals during COVID-19. PalArch's Journal of Archaeology of Egypt/ Egyptology PJAEE, 17 (7).

Novitasari,D., Sasono,I., \& Asbar,M.(2020). Work-Family Conflict and Worker's Performance during Covid-19 Pandemic: What is the Role of Readiness to Change International Journal of Science and Management Studies 
(IJSMS). International Journal of Science and Management Studies (IJSMS). E-ISSN: 2581-5946.

Rashmi, R. \& Vikas,B.(2020) .Impact of ergonomics on WFH productivity \& job satisfaction during COVID -19 period . Alochna Chakra Journal.

Schalk, R., Jennifer, W. Campbell \& Freese, C. (2014). Change and employee behaviour. Leadership \& Organization Development Journal. ISSN 0143-7739. 19/3 pp. 157-163.MCB university Press.

Singh, J., \& Jagandeep, S. 2020. COVID-19 and its impact on society. Electronic Research Journal of Social Sciences and Humanities, 2(1)/ 3567837 2020. https://ssrn.com/abstract=3567837

Singh, M.\& Kumar, V. (2020). Impact of Covid-19 Pandemic on Working Culture: An Exploratory Research Among Information Technology. Journal of Xi'an University of Architecture \& Technologies no. 1006-7930. Vol. 12 No. 5, pp.316

Singh, M., \& Kumar, V. (2020). Impact of COVID-19 pandemic on working culture: An exploratory research among information technology (IT) professionals in Bengaluru, Karnataka (India). Journal of X'ian University of Architecture \& technology. ISSN No.: 1006-7930.

Transmission of corona virus disease 2019 (COVID-19). Centres for Disease Control and Prevention, March 4, 2020. http://www.cdc.gov/coronavirus/2019-ncov/prepare/transmission.html

virus (sars-cov2). American Association for the Advancement of Science, 368(6490), 489-493.

Wai zenegger, L., Mc Kenna, B., Cai, Wenie., \& Bendz, T.( 2020) An affordance perspective of team collaboration and enforced Working from Home during COVID -19. European Journal of Information systems. ISSN: (Print) (Online) Journal homepage: https://www.tandfonline.com/loi/tjis20

zenegger,Y., L., Mc Kenna.,B., Wenie., \& Bendz,T.( 2020) An affordance perspective of team collaboration and enforced Working from Home during COVID -19. European Journal of 